\title{
Causes and anatomical site of blindness and severe visual loss in Isfahan, Islamic Republic of Iran
}

\author{
A. Dehghan, ${ }^{1}$ F. Kianersi, ${ }^{1}$ E. Moazam ${ }^{2}$ and H.Ghanbari
}

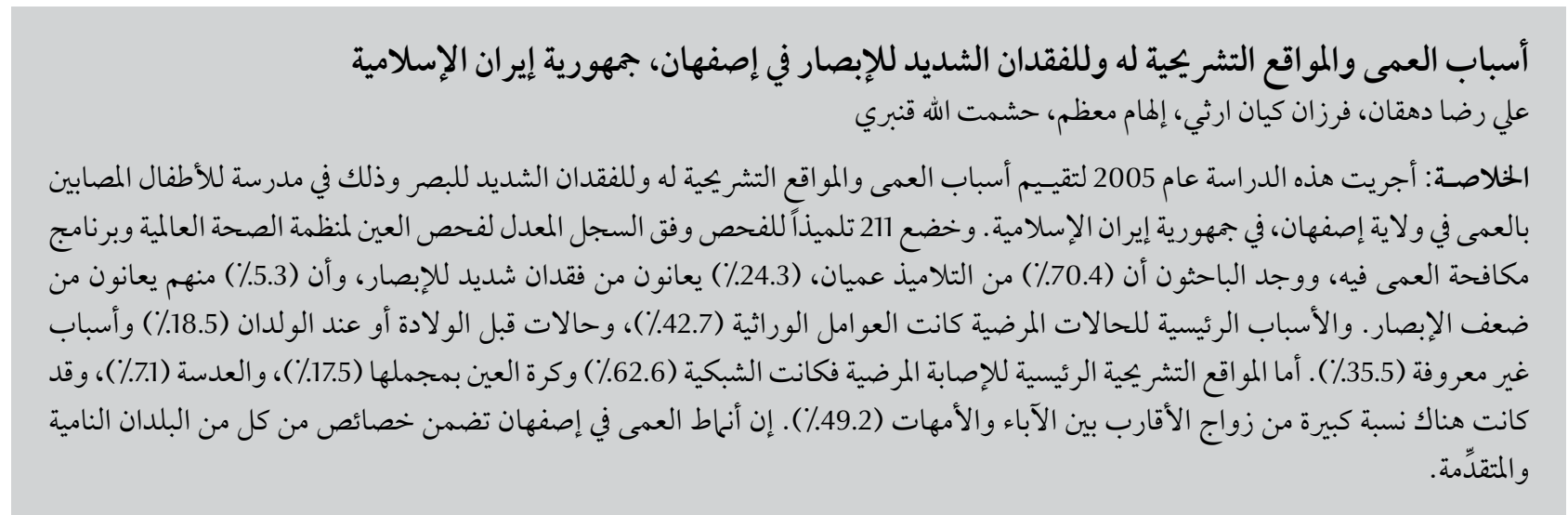

ABSTRACT This study in 2005 evaluated the causes and major anatomical site of blindness and severe visual loss at a school for blind children in Isfahan province, Islamic Republic of Iran. All 211 students were examined according to the modified WHO/PBL eye examination record: $70.4 \%$ were blind, $24.3 \%$ had severe visual loss and $5.3 \%$ were visually impaired. The major causes of abnormality were hereditary factors $(42.7 \%)$, prenatal/ neonatal (18.5\%) and unknown etiology (35.5\%). The main sites of abnormality were the retina $(62.6 \%)$, whole globe (17.5\%), lens (7.1\%) and optic nerve (7.1\%). A high proportion of parents were in a consanguineous marriage (49.2\%). The pattern of blindness in Isfahan encompasses characteristics of both developed and developing countries.

\section{Causes et localisation anatomique de la cécité et des pertes de vision sévères à Ispahan (République islamique d'Iran) \\ RÉSUMÉ La présente étude, conduite en 2005, évaluait les causes et les principales localisations anatomiques de la cécité et des pertes de vision sévères dans une école pour enfants aveugles de la province d'Ispahan en République islamique d'Iran. Les 211 écoliers ont tous été examinés suivant les indications de la fiche OMS/ PBL d'examen oculaire modifiée : 70,4\% étaient aveugles, 24,3\% avaient une perte de vision sévère, et 5,3\% souffraient de déficience visuelle. Les principales causes d'anomalie étaient des facteurs héréditaires (42,7\%), d'origine prénatale ou néonatale $(18,5 \%)$ et d'étiologie inconnue (35,5\%). Les anomalies étaient localisées essentiellement au niveau de la rétine $(62,6 \%)$, de l'ensemble du globe oculaire $(17,5 \%)$, du cristallin $(7,1 \%)$ et du nerf optique (7,1\%). Parmi les parents, une forte proportion avait contracté un mariage consanguin (49,2\%). À Ispahan, les caractéristiques de la cécité recouvrent aussi bien celles des pays développés que celles des pays en développement.}




\section{Introduction}

According to the World Health Organization (WHO), an estimated 1.5 million children worldwide are blind, two-thirds of them in Asia. In developing nations, $30 \%-72 \%$ of childhood blindness is avoidable [1]. Therefore, the control of blindness in children is considered a high priority within the WHO's VISION 2020: the Right to Sight initiative [2]. The major causes of blindness vary widely from region to region, being largely determined by socioeconomic development and the availability of primary health care and eye services. In the poorest countries of the world, corneal scarring due to vitamin A deficiency, measles infection, ophthalmia neonatorum, and the effects of harmful traditional eye remedies predominate. Perinatal conditions [particularly retinopathy of prematurity (ROP)] and lesions of the central nervous system) are more important in high-income countries. In middle-income countries, the picture is mixed, with ROP emerging as an important avoidable cause of blindness. In all regions of the world, cataract, retinal diseases and congenital abnormalities affecting the whole globe are important causes of blindness [3].

Examination of children in special education centres has increasingly been used to provide data on the causes of blindness. Studieshave beenundertaken in schools for blind children in various countries using the WHO Programme for Prevention of Blindness (WHO/ $\mathrm{PBL}$ ) record, which has standard definitions and allows comparison of the collected data [3].

Valid disease registers are not developed in the Islamic Republic of Iran, except for cancer. Two studies in schools for the blind have been conducted in Tehran and Shiraz $[4,5]$. However, there is a lack of data on the pattern of childhood blindness in Isfahan, one of the largest and most industrialized provinces of the country. The purpose of the present study was to determine the causes and anatomical sites of blindness in the Ababasir School for the Blind in Isfahan. It was hoped that the data could be used for planning appropriate interventions for prevention and management of avoidable causes of blindness in children in the region and provide baseline data for monitoring changes in the pattern of causes of childhood blindness over time.

\section{Methods}

In this descriptive study, the Ababasir School for the Blind was visited during the academic year 2006, between October 2005 and June 2006, after obtaining permission for the study from the school principals. Ababasir is the only government school for blind children in Isfahan province. Students are at primary and middle grades. The school is located in the northern district of Isfahan. Some students from neighbouring provinces also attend the school.

All children attending the school were examined. They were invited in small groups to come into the eye department at Feiz Hospital for investigation. Parents were present on the day their child was examined. One of the researchers went to the school and completed gaps in the data.

Information was gathered using interviews with students, parents and school staff and by consulting the hospital and community health records for each child. A brief history of the age of onset of visual loss, family history, history of consanguinity and place of residence (village, town or city) was recorded.

Three of the authors undertook detailed eye examinations. The Snellen illiterate E optotype was used to measure visual acuity levels of $6 / 18,6 / 60$ and $3 / 60$ with available correction. If a child could not see the 3/60 optotype, he/ she was checked for perception of light. Near vision was assessed using figures equivalent to N18. The findings of simple tests of functional vision - the ability to walk unaided around chairs set $2 \mathrm{~m}$ apart, to recognize faces at a distance of $3 \mathrm{~m}$, and to recognize the shape of $32 \mathrm{~cm}$ symbols at any near distance - were recorded. Anterior segment examination was performed using a slit lamp or flashlight and magnifying lens. Posterior segment examination was performed by indirect or direct ophthalmoscopy after mydriasis (except where inappropriate).

The WHO/PBL eye examination record for children with blindness and low vision was used [6]. This classifies cause according to the main anatomical site of the abnormality as well as the underlying etiology.

The data were entered into a database and analysed using SPSS software.

\section{Results}

A total of 211 students were examined. The mean age was 11.02 [standard deviation (SD) 3.2] years, range 5-19 years. There were 133 males (63.1\%) and 78 females (36.9\%). Nearly half the children had parents who were in a consanguineous marriage (49.3\%), predominantly cousins.

The students were categorized according to their visual acuity into 3 groups: $70.1 \%$ were blind, $24.3 \%$ were severely visually impaired and $5.7 \%$ were visually impaired according to the $\mathrm{WHO} / \mathrm{PBL}$ categories. About 60\% had suffered blindness or severe visual impairment from birth. There was a positive family history of another similarly affected individual in 62 (29.4\%) children. History of previous eye surgery was noted in $13(6.2 \%)$ students. Trauma was the cause of surgery in 7 and cataract in 3 .

The site of abnormality leading to visual loss or its anatomical classification 


\begin{tabular}{|c|c|c|}
\hline \multicolumn{3}{|c|}{$\begin{array}{l}\text { Table } 1 \text { Anatomical site and etiological } \\
\text { classification based on time of onset of } \\
\text { visual loss of severe visual impairment } \\
\text { and blindness in } 211 \text { children attending } \\
\text { Ababasir School for the Blind in } \\
\text { Isfahan }\end{array}$} \\
\hline Variable & $\begin{array}{l}\text { No. of } \\
\text { children }\end{array}$ & $\%$ \\
\hline \multicolumn{3}{|l|}{ Site of abnormality } \\
\hline Retina & 132 & 62.6 \\
\hline Whole globe & 37 & 17.5 \\
\hline Lens & 15 & 7.1 \\
\hline Optic nerve & 15 & 7.1 \\
\hline Cornea & 9 & 4.3 \\
\hline Uvea & 3 & 1.4 \\
\hline \multicolumn{3}{|l|}{ Etiology } \\
\hline Hereditary disease & 90 & 42.7 \\
\hline Intrauterine factor & 2 & 0.9 \\
\hline $\begin{array}{l}\text { Perinatal/neonatal } \\
\text { factor }\end{array}$ & 39 & 18.5 \\
\hline $\begin{array}{l}\text { Postnatal/infancy } \\
\text { factor }\end{array}$ & 5 & 2.4 \\
\hline Unknown & 75 & 35.5 \\
\hline
\end{tabular}

is shown in Table 1. The site of abnormality was the retina in $62.6 \%$, whole globe in $17.5 \%$, lens, optic nerve, cornea and uvea in $7.1 \%, 7.1 \%, 4.3 \%$ and $1.4 \%$ respectively. There were $15(7.1 \%)$ cases of congenital glaucoma, 31 (14.7\%) cases of cone red dystrophy and 10 (4.7) cases of Leber's congenital amaurosis. Optic atrophy accounted for $7.1 \%$, and retinal detachment for $4.7 \%$. ROP was seen in only $0.9 \%$ of children. The major causes of blindness and severe visual impairment were hereditary factors in $42.7 \%$, prenatal/neonatal in $18.5 \%$ and unknown etiology in $35.5 \%$ of students (Table 1).

The majority of children (86.3\%) had no disability apart from blindness. Mental retardation or epilepsy were the most common defined additional impairment, present in 8 (3.8\%) children.

The majority of students were from Isfahan (city) (41.9\%), followed by Khomeinishahr (Sedeh) (18.1\%) and Mobarakeh (6.7\%). The populationadjusted prevalence of blindness was much higher in Khomeinishahr (13.3 per 100 000) and Mobarakeh (10.4 per 100000$)$ compared with the other districts (Table 2).

\section{Discussion}

Most of the available data on the causes of blindness in children from developing countries have been obtained from examining children in schools for the blind, since the number of blind children identified in community surveys

\begin{tabular}{lccc}
\hline $\begin{array}{l}\text { Table } 2 \text { Population-adjusted prevalence of blindness per 100 000 } \\
\text { Isfahan }\end{array}$ & $\begin{array}{c}\text { No. of } \\
\text { children }\end{array}$ & Population size & $\begin{array}{c}\text { Prevalence of } \\
\text { blindness per } \\
\mathbf{1 0 0 ~ 0 0 0}\end{array}$ \\
\hline District & 38 & 286543 & 13.3 \\
Khomeinishahr & 14 & 134869 & 10.4 \\
Mobarakeh & 88 & 1984689 & 4.4 \\
Isfahan & 8 & 233047 & 3.4 \\
Falavarjan & 2 & 64125 & 3.1 \\
Tiran \& Karvan & 1 & 32114 & 3.1 \\
Khansar & 2 & 67943 & 2.9 \\
Semirom & 1 & 39259 & 2.6 \\
Fereidonshahr & 7 & 278253 & 2.5 \\
Borkhar \& Meime & 2 & 86479 & 2.3 \\
Fereydan & 1 & 44938 & 2.2 \\
Natans & 4 & 226363 & 1.8 \\
Lenjan & 2 & 282752 & 0.7 \\
Najafabad & 41 & - & - \\
Other & & & \\
\hline
\end{tabular}

is generally very small. [3]. For example, in the Tehran Eye Study in which a population of 4565 was examined, only 0.14-0.42 were blind and none of them were in the age group 0-19 years [7]. Titiyal et al. argue that "Blind school studies have the advantage that a large number of children can be examined in a short time, are relatively inexpensive, can be done by a single observer, and provide an indication of relative importance of the different causes of blindness" [8]. However, they also point out that they "are subject to certain inherent biases: children less than 5 years of age, those with multiple disabilities, and those from lower socioeconomic groups or from rural communities are likely to be under-represented, as are causes in children who have died". In other words children in schools for the blind may not be representative of blind children in the whole population.

It is likely that a majority of blind children in Isfahan attend the Ababasir School for the Blind, as it is the only government school and there are no fees for studying there. Most of the children in this study came from different regions of the province and neighbourhing provinces. A high proportion of children came from 3 city regions - Isfahan, Khomeinishahr and Mobarakeh - which is not a reflection of the number of children in those cities. For example, very few students came from Najafabad or Lenjan, which have similar population size and socioeconomic/cultural status. Further studies with spatial analysis of probable risk factors are recommended.

There were more males $(63.1 \%)$ than females in the school. The preponderance of males probably reflects the cultural barriers for female children in society, rather than a real difference in prevalence of blindness between the sexes. In the Tehran Eye Study, the distribution of low vision was not statistically significantly different between men and women [7]. 


\begin{tabular}{|c|c|c|c|c|c|c|}
\hline \multicolumn{7}{|c|}{$\begin{array}{l}\text { Table } 3 \text { Comparison of the anatomical sites of blindness and severe visual loss in } \\
\text { different studies }\end{array}$} \\
\hline \multirow{3}{*}{$\begin{array}{l}\text { Anatomical } \\
\text { site }\end{array}$} & \multicolumn{3}{|c|}{ Islamic Republic of Iran } & \multirow{3}{*}{$\begin{array}{c}\text { China } \\
{[9]} \\
\%\end{array}$} & \multirow{3}{*}{$\begin{array}{c}\text { Ethiopia } \\
\text { [10] } \\
\%\end{array}$} & \multirow{3}{*}{$\begin{array}{c}\text { United } \\
\text { Kingdom } \\
{[17]} \\
\%\end{array}$} \\
\hline & $\begin{array}{l}\text { Isfahan } \\
\text { (present study) }\end{array}$ & Tehran $[4]$ & Shiraz [5] & & & \\
\hline & $\%$ & $\%$ & $\%$ & & & \\
\hline Retina & 62.5 & 51.3 & 54.5 & 24.9 & 2.4 & 36.0 \\
\hline Cornea & 4.2 & 8.8 & 6.2 & 4.4 & 62.4 & 1.0 \\
\hline Whole globe & 17.5 & 12.2 & 21.4 & 34.5 & 6.4 & 13.0 \\
\hline Lens & 7.1 & 13.5 & 7.2 & 18.8 & 9.2 & - \\
\hline Optic nerve & 7.1 & 10.2 & 1.4 & 13.6 & 9.8 & 50.0 \\
\hline Uvea & 1.4 & 1.7 & - & 1.5 & 8.8 & - \\
\hline Other & - & 2.3 & 9.3 & 2.3 & 1.0 & - \\
\hline
\end{tabular}

Among 211 pupils examined, 94.8\% hadsevere visualimpairment/blindness. This proportion of children is higher than the reports from Shourideh School for the Blind in Shiraz (92\%) and in north India (92\%). In blind schools in Tehran, this proportion was 95\% $[4,5,8]$. In the present study, only $13.7 \%$ of children had an additional disability, which is very low compared with developed countries, however, children with multiple disabilities do not usually enter Ababasir school, and therefore cases of visual loss with other disabilities tend to be under-represented.

Studies in schools for the blind have been undertaken in various countries using the standard $\mathrm{WHO} / \mathrm{PBL}$ form and have found a varied spectrum of causes of blindness in children [4-15]. The anatomical sites of blindness and severe visual loss in studies from different countries are compared in
Table 3. The pattern of anatomical site of severe visual impairment/blindness in the present study is similar to other Iranian studies $[4,5]$. The proportion of students with retinal abnormality in the Islamic Republic of Iran was much greater than the other countries $[9-11]$. Corneal lesions were much lower in Isfahan and other parts of the Islamic Republic of Iran than in Ethiopia. The relative rarity of corneal and nutritional conditions and infectious disorders was similar to reports from developed countries. However, as in other studies in blind schools in developing countries this study was prone to selection bias towards ocular disease [11]. Therefore blindness in the Islamic Republic of Iran has the characteristics of both developed and developing countries.

The etiology of severe visual impairment/blindness is compared in different studies from different regions in Table 4.

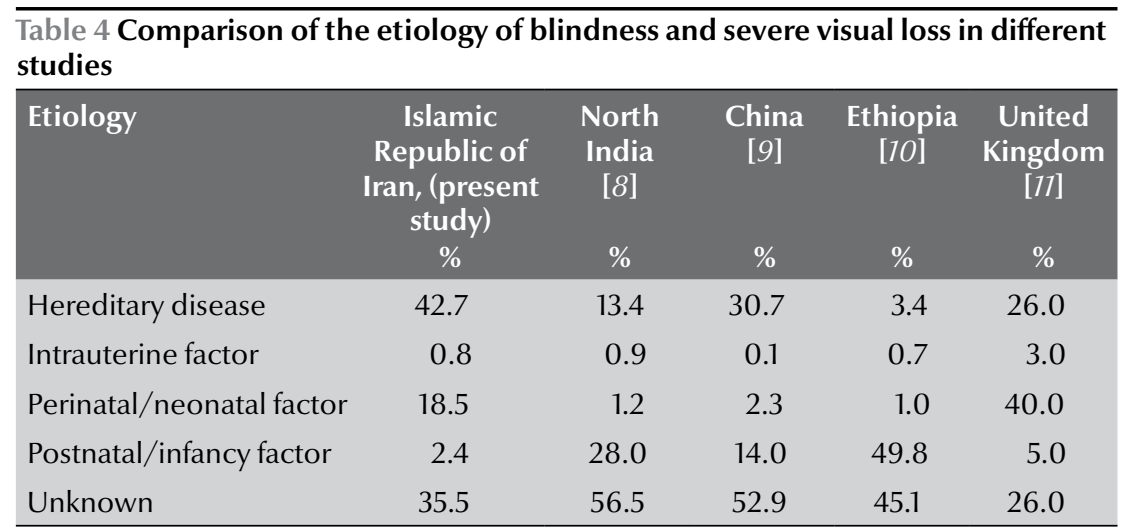

Hereditary factors were a much greater cause of blindness in the present study compared with other countries. Almost $50 \%$ of parents of our children had a positive history of consanguineous marriage. The practice of consanguineous marriage to first cousins increases the frequency of genetic causes of blindness [16]. The data showed a mixed pattern between hereditary and unknown etiologies (a pattern similar to that in industrialized countries) [17].

In the Tehran study, Leber's amaurosis was the most common disease, present in $44 \%$ of students [4]. Lebers congenital amaursis (4.7\%) and cone rod dystrophy (14.7\%) were more frequent in the present study compared to other countries $[1,18]$. The frequency of genetic disorders lay between the rates seen in developing countries and those in developed countries.

The low incidence of ROP found in our study is probably the result of the much higher mortality of premature children in the Islamic Republic of Iran compared to developed countries [19]. There are insufficient beds in neonatal intensive care units in Isfahan. In the blind school study in Shiraz, hereditary retinal degeneration was demonstrated to be the most common cause of blindness. This was attributed to the high rate of consanguineous marriage [5], a hypothesis that agrees with the results of our study.

Counselling about consanguineous marriage is recommended for reducing the risk of severe visual impairment/ blindness in Isfahan province. Screening programmes in the target age groups are also recommended for prevention of avoidable causes. 


\section{References}

1. Steinkuller PG et al. Childhood blindness. Journal of the American Association for Pediatric Ophthalmology and Strabismus, 1999, 3:26-32.

2. Global initiative for the elimination of avoidable blindness. Geneva, World Health Organization, 1997 (WHO/PBL/97.61).

3. Gilbert C, Foster A. Childhood blindness in the context of VISION 2020: the right to sight. Bulletin of the World Health Organization, 2001, 79(3):227-32.

4. Mirdehghan SA et al. Causes of severe visual impairment and blindness in schools for visually handicapped children in Iran. British journal of ophthalmology, 2005, 89:612-4.

5. Mehdizadeh M, Afarid M, Attarzadeh A. Causes of childhood blindness among students of blinds school in Shiraz, Iran. Iranian journal of medical sciences, 2005, 30(2):55-8.

6. Gilbert C, Faster A, Negrel AD. Childhood blindness: a new form for recording causes of visual loss in children. Bulletin of the World Health Organization, 1993, 71:485-9.

7. Fotouhi A et al. The prevalence and causes of visual impairment in Tehran: the Tehran Eye Study. British journal of ophthalmology, 2004, 88:740-5.

8. Titiyal JS et al. Causes and temporal trends of blindness and severe visual impairment in children in schools for the blind in North India. British medical journal, 2003, 87:941-5.

9. Hornby $\mathrm{S}$ et al. Causes of blindness in People's Republic of China: results from 1131 blind school students in 18 provinces. British journal of ophthalmology, 1999, 83:929-32.

10. Kello AB, Gilbert C. Causes of severe visual impairment and blindness in children in schools for the blind in Ethiopia. British medical journal, 2003, 87:526-30.
11. Alagaratnam J et al. A survey of visual impairment in children attending the Royal Blind School, Edinburgh using the WHO childhood visual impairment database. Eye, 2002, 16:557-61.

12. Kocur I et al. Causes of severe visual impairment and blindness in children attending schools for the visually handicapped in the Czech Republic. British journal of ophthalmology, 2001, 85:1149-52.

13. Reddy SC, Tan BC. Causes of childhood blindness in Malaysia: results from a national study of blind school students. International ophthalmology, 2001, 24(1):53-9.

14. Akinsola FB, Ajaiyeoba Al. Causes of low vision and blindness in children in a blind school in Lagos, Nigeria. West African journal of medicine, 2002, 21(1):63-5.

15. Gilbert CE et al. Causes of childhood blindness in east Africa: results in 491 pupils attending 17 schools for the blind in Malawi, Kenya and Uganda. Ophthalmic epidemiology, 1995, 2:77-84.

16. Thomas AW et al. Pediatric blindness. In: International ophthalmolog. Basic and clinical science course. Philadelphia, American Academy of Ophthalmology, 2002-2003:75-82.

17. Gilbert $C$ et al. Hereditary disease as a cause of childhood blindness: regional variation. Ophthalmic genetics, 1995, 16:1-10.

18. Isenberg $\mathrm{S}$ et al. International childhood blindness. Journal of the American Association for Pediatric Ophthalmology and Strabismus, 2009, 13(1):e34.

19. Mortality country fact sheet 2006. Iran (Islamic Republic of). World Health Organization [online report] (www.who.int/ whosis/mort/profiles/mort_emro_irn_iran.pdf, accessed 15 September 2009).

\section{Note from the Editor}

We wish to draw the kind attention of our potential authors to the importance of applying the editorial requirements of EMHJ when preparing their manuscripts for submission for publication. These provisions can be seen in the Guidelines for Authors, which are available online at http:/ /www.emro.who.int/emhj.htm, and are published at the end of the first issue of each volume. We regret that we are unable to consider papers that do not conform to the Guidelines. 